
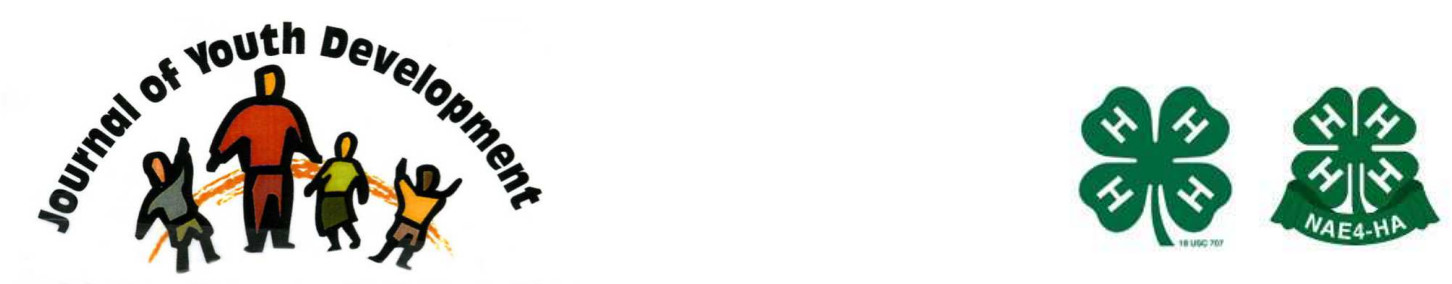

Bridging Research \& Practice

\title{
Parental Attachment and Eating Behaviors in Late Adolescent Females
}

\author{
Amber-Leigh Rush \\ Capstone College of Nursing \\ The University of Alabama \\ Tuscaloosa, AL \\ Alice L. March \\ Capstone College of Nursing \\ The University of Alabama \\ Tuscaloosa, AL \\ almarch@bama.ua.edu
}




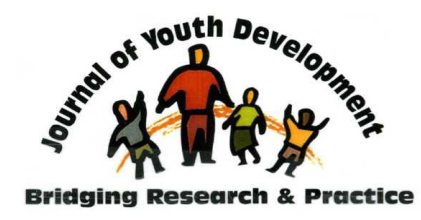

Volume 7, Number 4, Winter 2012

\section{JOURNAL OF YOUTH DEVELOPMENT \\ bridging research and practice}

\title{
Parental Attachment and Eating Behaviors in Late Adolescent Females
}

\author{
Amber-Leigh Rush and Alice L. March \\ The University of Alabama
}

\begin{abstract}
Females demonstrating unhealthy eating behaviors in early adolescence may continue to exhibit them in later years, yet there is little empirical research including late adolescents. Attachment theories suggest that adolescents with eating disorders demonstrate insecure attachments to parents. This non-experimental descriptive study in 249 late adolescent females examined the relationship between eating behaviors and parental attachment, and explored the relationship between selected demographic variables and parental attachment. Participants responded to an electronically collected survey of demographic variables, self-reported eating behaviors, and completed the Parent Attachment Questionnaire. Participants reporting healthy eating behaviors had higher scores on two of the three maternal scales, indicating a greater level of attachment. Significantly higher scores were found for two maternal and two paternal attachment scales for selected sociodemographic variables. Quantifying parental attachment in late adolescent females enhances understanding of eating disorders in this population and may help to identify issues important to address in therapy.
\end{abstract}

\section{Introduction}

Hospitalizations related to eating disorders are increasing in the United States. Between 1999 and 2005 the combined rates for all eating disorder hospitalizations increased by $18 \%$ and the related costs of $\$ 271$ million represents an increase of $61 \%$. One in four of people hospitalized in 2005 for eating disorders had cardiac dysrhythmias and 4\% had liver or renal failure. Both statistics represent a greater than $100 \%$ increase in a six year period and not surprisingly the age group with the highest rate of admission (27\%) was from 19 to 30 years of age, with female admission rates higher than male admission rates (Zhao \& Encinosa, 2009). Eating disorders are not uncommon among late adolescent females, and as evidenced by the previous statistics, the immediate and long term personal health issues and financial burden of this 
problem can be devastating. Fortunately, prevalence rates of anorexia nervosa, bulimia nervosa, and binge eating disorders in females without hospital admissions are low at $0.9 \%$, $1.5 \%$, and 3.5\%; respectively however, this compares unfavorably in relation to the prevalence rates of men; $0.3 \%, 0.5 \%$, and $2.0 \%$, respectively (Hudson, Hiripi, Pope, \& Kessler, 2007).

Eating disorders in high school aged females have been extensively researched due to the relatively high prevalence in this population (Forrest \& Forrest, 2008; Rafiroiu, et al., 2007). Sociodemographic risk factors for the development of eating disorders include younger age, female gender, and Caucasian race (Pratt \& Woolfenden, 2002). Other risk factors are athleticism, sorority membership, and a number of psychological variables (Basow, Foran, \& Bookwala, 2007; Berry \& Howe, 2000; Cooley \& Toray, 2001). Adolescent females' weight concerns heighten around 16 years of age and usually begin to decrease as they grow older. Yet females who demonstrate eating disorder behaviors in high school may continue to exhibit them in later adolescence and during adulthood (May, Kim, McHale, \& Crouter, 2006). There is little empirical research describing the variables surrounding eating disorder behaviors in this population.

The purpose of this non-experimental, descriptive study of late adolescent females was to examine the relationship between healthy eating behaviors and parental attachment, and whether attachment was the same for both parents. Because the researchers were interested in other aspects of parental attachment a secondary purpose of the study was to explore the relationship between certain sociodemographic factors and parental attachment, and whether those factors were the same for both parents.

\section{Guiding Framework}

Attachment theory posits that an attachment figure, usually a parent, is a source of support for a child to explore the environment. The responsibility of the attachment figure is to provide a secure base from which the child can explore. The child is independent during the time of exploration yet can come back to the attachment figure when needing encouragement and aid (Kenny \& Hart, 1992). The child seeks this encouragement and aid from the attachment figure during stressful events. The child does not possess the coping skills to deal effectively with the stressful events, and the attachment figure acts as a buffer aiding in the restoration of a sense of safety. After the sense of safety is reestablished, the child can continue to survey and interact with the environment at a safe distance from the parent (Vivona, 2000).

Attachment styles include one positive attachment style referred to as secure, and two insecure styles; avoidant and ambivalent. The child who demonstrates secure attachment successfully uses the parent as a base for exploration of the environment, which allows the child to develop autonomy (Kenny \& Hart, 1992). In avoidant attachment the child seeks distance from the parent because the parent is considered invasive and/or indifferent. The parent may be perceived to be neglectful and interfering with the child's exploration in the ambivalent attachment style, which results in the child's inability to identify a secure distance from the parent (Vivona, 2000).

Insecure attachment occurs when a child feels that the safety needs are not met by the parent (Gutzwiller, Oliver, \& Katz, 2003). Insecure attachment has been linked to poor academic outcomes and impaired psychological well-being (Eggert, Levendosky, \& Klump, 2007; Kenny \& Sirin, 2006). Late adolescence and early adulthood are vital developmental stages for exploration of self and separation from parents (Gutzwiller, et al.), and it is at this time that young females may experience the onset of or a worsening in unhealthy eating behaviors. 
Food is a means of sustenance, and is a vital component of attachment to parents (Dallos \& Denford, 2008). Hunger produces distress in the child, and the way in which the parent responds to the child's need for food determines the degree of care and comfort the child perceives that he or she can expect from the parent. Children learn that food is used by the parent to express love and affection or punishment and distancing. Because food can be used to express love and affection, this creates a secure base of attachment and unhealthy eating behaviors may be a demonstration of impaired parental attachment (Dallos \& Denford, 2008).

\section{Literature Review}

The literature includes studies involving the eating behaviors of late adolescent females including female athletes (Berry \& Howe, 2000) and sorority members related to the onset or worsening of eating disorders during college (Basow, et al., 2007). Body dissatisfaction prior to graduating from high school predicted worsening eating patterns during college, and multiple factors such as poor self-perception, increased stress, low self-esteem, depression, and other psychological features were associated with both onset and continuation of eating disorders during college (Cooley \& Toray, 2001). Other factors such as the developmental stresses of transitioning into adulthood, which includes leaving home and changing living situations, distances the woman from supportive and involved parents, and may contribute to new or worsening unhealthy eating behaviors, whether that youth attends college or enters the job market (Gutzwiller, et al., 2003).

Parental attachment theory suggests that secure attachment allows the child to explore the environment because a secure base to return to has been established (Kenny \& Hart, 1992). If this is true, late adolescent females who demonstrate healthy eating behaviors should report greater levels of secure attachment to one or both parents and less interpersonal problems. For the purposes of this study the researchers define late adolescence as ages 18 to 25 years of age, using assumption of an adult role (graduation from college) as the endpoint of adolescence (Jessor, 1998). A study examining parental attachment found that adolescent females with significant weight concerns were more likely to report increased frequency of interpersonal conflict and poor relationships with mothers (May, et al., 2006). Studies examining parental attachment and eating disorders among older adolescents exist, but few examine both attachment and eating behavior, and even fewer report maternal attachment separate from paternal attachment. For example, one study of eating disorders in female college athletes did not explore parental attachment (Berry \& Howe, 2000).

As noted, research related to the parent-child relationship of females with eating disorders has focused either on the attachment style with the mother or the attachment style with the father, rather than both parents in the same study (Dallos \& Denford, 2008; Gutzwiller, et al., 2003). For example, one study explored isolation from fathers, which was associated with insecure attachment, but no maternal variables were collected. Daughters who feel ignored and rejected by the father may develop poor or ambivalent attachment, and the father's lack of involvement causing the insecure attachment is posited to be a contributing factor in the development of eating disorders (Gutzwiller, et al., 2003).

In studies that examined both maternal-child and paternal-child attachment there was no clear evidence suggesting whether the attachment style of either parent was more likely to lead to problems with eating disorders (May, et al., 2006; Tereno, Soares, Martins, Celani, \& Sampaio, 2008). One study reported common themes among families (Dallos \& Denford, 2008). In adolescents with eating disorders, the mother of the teen was more likely to report an insecure attachment with her own mother while growing up. This suggests that the attachment style the 
adolescent's mother had with the grandmother may continue forward and be demonstrated in the relationship with the daughter (Dallos \& Denford). The overall numbers of studies examining the onset, worsening, or continuation of eating disorders in late adolescent females are limited and further study of eating behaviors in late adolescence is needed.

\section{Hypotheses and Research Questions}

The first hypothesis of this study was that late adolescent females reporting healthy eating behaviors will have higher mean scores on the Parental Attachment Questionnaire (PAQ) scales when compared with females who do report those behaviors. The related research question was: What is the relationship between parental attachment and healthy eating behaviors in late adolescent females? The second hypothesis, that certain sociodemographic variables are associated with parental attachment leads to the second research question: What are the sociodemographic factors related to parental attachment?

\section{Methods}

\section{Sample}

This was a convenience sample of randomly selected female college students at a university in the southern region the United States. An email explaining the survey and obtaining consent was sent to 1668 students. Inclusion criteria included female sex, status as a full-time student, and age 19 to 25 years old. Exclusion criteria included females who were registered as exclusively distance learning students, which indicates that they are expected to be in a graduate program of study.

\section{Procedure}

After obtaining human subject protection approval, the registrar's office provided a list of email addresses for enrolled female students who met the inclusion criteria. A random number procedure selected participant addresses from the original list, and an email recruitment letter was sent inviting students to participate in the study. The email included a description of the study, a consent form, and a link to the actual survey. To assure confidentiality access to the survey required no personal information. The first page of the survey included an additional copy of the informed consent information, and before a participant could advance to the survey, the participant selected an option acknowledging that she had read the informed consent, and understood her protected rights.

A 17 item sociodemographic questionnaire collected data including age, race, credit hours completed, and grade point average. The questionnaire included items about rural versus suburban/urban residency during her formative years. Other variables included the state of permanent residence (i. e. Alabama), number of siblings, marital status, employment, and source of financial support. Previous research demonstrated insecure attachment in children of divorced parents; therefore parental marital status was included (Crowell, Treboux, \& Brockmeyer, 2009). Sorority membership was included based on its identification as a contributing factor in eating disorders (Basow, et al., 2007). The sociodemographic variables were included to better describe the sample, explore possible relationships, and to provide groups for comparison.

\section{Self-Assessment of Eating Behaviors Questionnaire}

The Eating Behaviors Questionnaire was composed of 15 investigator created questions and identified eating behaviors such as, type of diet the participant followed, number of meals per day, and number of times during the past year a weight loss diet was started. The main goal of 
the study was to investigate behaviors associated with healthy eating therefore the only eating behaviors items that were examined during analysis were no reports of self-induced vomiting (coded as yes or no) and number of meals per day (recoded to 1 or 2 meals per day, and 3 or more meals per day). These behaviors have been identified in previous studies as risky weightcontrol behaviors (Forrest \& Forrest, 2008; Rafiroiu, et al., 2007).

\section{Parental Attachment Questionnaire}

The PAQ, a 55-item questionnaire, assessed participant's perceptions of the relationship with each parent as a rating measurement of attachment (Kenny, 1987). Separate responses were collected for the mother and the father for each item and were scored on a 5-point Likert scale ranging from 1 (not at all) to 5 (very much). Scale score totals ranged from 13 to 135, with higher scores indicating a greater level of secure parental attachment. The three subscales, Affective Quality of Relationship (27 items), Parent as Facilitator of Independence (14 items), and Parent as Source of Support (13 items), measured specific aspects of attachment (Kenny, 1994).

Previously reported reliability includes test-retest reliability of the Parental Attachment Questionnaire of 0.92 (Kenny, 1987), and Cronbach's alphas for internal consistency have ranged from .93 to .96 (Frey, Beesley, \& Miller, 2006; Kenny, 1987; Kenny \& Sirin, 2006). Validity was established by moderate correlation to similar concepts (Holmbeck \& Wandrei, 1993; Kenny \& Donaldson, 1991), and concurrent and convergent validity has been examined (Kenny \& Donaldson, 1991).

\section{Results}

\section{Statistical Analysis}

The analysis software, SPSS version 18, was used to complete the statistical analysis. Frequencies examined the descriptive sociodemographic data. The inferential statistic that determined the differences in mean scores on the PAQ was independent t-test. The initial sample of 260 students yielded a final sample of 249. A number of students started the survey, but stopped when they encountered the eating behavior questions. The group that completed only the sociodemographic portion of the study was not significantly different in any demographic categories from the participants completing the entire survey.

\section{Findings}

Of the 1668 emails sent 260 students participated in the survey, resulting in a response rate of approximately $16 \%$. Online survey rates vary, and can be as low as $20 \%$ (Ellison, Bradshaw, Rote, Storch, \& Trevino, 2008), or as high as 60\% (Pealer, Weiler, Pigg, Miller, \& Dorman, 2001). Frequencies described the sociodemographic makeup of the final sample. Consistent with the university's enrollment for female students between 19 years of age and 25 years of age there were $84.7 \%$ Caucasian, $7.2 \%$ Black, 1.6\% Asian, and 0.4\% Native American participants. Two thirds of the participants reported married parents. Although almost half of the sample was employed at least part time, nearly two thirds reported parents as the main source of financial support. Only one in ten lived at home and one in four was a sorority member (Table 1). 
Table 1

Table of Selected Demographic Variable

\begin{tabular}{|l|c|c|}
\hline Demographics* & Yes & No \\
\hline Parents Married & $66.3 \%$ & $26.9 \%$ \\
\hline Financially parent-supported & $30.9 \%$ & $63.1 \%$ \\
\hline Employed & $45.0 \%$ & $50.2 \%$ \\
\hline Resident of Alabama & $70.7 \%$ & $22.9 \%$ \\
\hline Residing in Home & $7.2 \%$ & $87.6 \%$ \\
\hline Sorority member & $22.5 \%$ & $72.3 \%$ \\
\hline
\end{tabular}

* For the categories that do not equal $100 \%$, the missing percentages represent the participants who did not provide a response for that question.

In examining the hypothesis, that late adolescent females who report healthy eating behaviors will have higher mean scores on PAQ scales, when compared with females who do report those behaviors, the analyses supported the directional hypothesis. Statistically significant differences in mean score on maternal attachment scales were found for three or more meals eaten per day and no self-induced vomiting (Table 2). Mean scores on the Maternal Independence Scale were higher for the group who did not report self-induced vomiting, and significant differences in the scores for number of meals eaten per day were found for the Maternal Relationship Scale. The group of participants that reported three or more meals per day had higher mean scores, indicating a higher level of maternal attachment.

Table 2

Table of Selected Maternal Scale Findings*

\begin{tabular}{|c|c|c|c|c|c|c|c|}
\hline \multirow[b]{2}{*}{ Category } & \multirow[b]{2}{*}{ Response } & \multicolumn{2}{|c|}{$\begin{array}{c}\text { Maternal } \\
\text { Support } \\
\text { Scale }\end{array}$} & \multicolumn{2}{|c|}{$\begin{array}{c}\text { Maternal } \\
\text { Independence Scale }\end{array}$} & \multicolumn{2}{|c|}{$\begin{array}{c}\text { Maternal } \\
\text { Relationship Scales }\end{array}$} \\
\hline & & Mear & $p$ & Mean & $p$ & Mean & $p$ \\
\hline $\begin{array}{l}\text { Formative years } \\
\text { residency }\end{array}$ & $\begin{array}{l}\text { Rural } \\
\text { Other }\end{array}$ & $\begin{array}{l}46.6 \\
45.5\end{array}$ & 0.011 & $\begin{array}{l}59.44 \\
56.99\end{array}$ & 0.028 & & \\
\hline $\begin{array}{l}\text { Parent's marital } \\
\text { status }\end{array}$ & $\begin{array}{l}\text { Married } \\
\text { Not married }\end{array}$ & $\begin{array}{l}46.7 \\
44.0\end{array}$ & & & & $\begin{array}{l}114.69 \\
110.63\end{array}$ & 0.020 \\
\hline $\begin{array}{l}\text { Number of meals } \\
\text { per day }\end{array}$ & $\begin{array}{l}\text { More than } 3 \\
\text { Less than } 3\end{array}$ & & & & & $\begin{array}{l}115.97 \\
108.39\end{array}$ & 0.020 \\
\hline $\begin{array}{l}\text { Self-induced } \\
\text { vomiting }\end{array}$ & $\begin{array}{l}\text { No } \\
\text { Yes }\end{array}$ & & & $\begin{array}{l}13.100 \\
9.778\end{array}$ & 0.020 & & \\
\hline
\end{tabular}

* For the categories that do not equal $100 \%$, the missing percentages represent the participants who did not provide a response for that question. 
In answer to the second research question: What sociodemographic factors are related to differences in mean scores of maternal and paternal attachment scales as assessed by the PAQ, the study found statistically significant differences in mean scores on maternal attachment scales for formative years residency and parent's marital status (Table 2). Mean scores on the Maternal Support Scale and the Maternal Independence Scale were higher for the group who reported formative years as rural and mean scores on the Maternal Support Scale and the Maternal Relationship Scale were higher for the group with married parents.

There were no significant differences in the mean scores on paternal scales to support the hypothesis that late adolescent females who report healthy eating behaviors will have higher mean scores on the PAQ. In answer to the research question considering sociodemographic factors related to differences in mean scores of paternal attachment, the study found statistically significant differences in mean scores for source of financial support and parent's marital status (Table 3). Mean scores on the Paternal Independence Scale and the Paternal Relationship Scale were higher for the group who reported parents as the source of income and for those reporting married parents.

Table 3

Table of Selected Paternal Scale Findings*

\begin{tabular}{|c|c|c|c|c|c|c|c|}
\hline \multirow[b]{2}{*}{ Category } & \multirow[b]{2}{*}{ Response } & \multicolumn{2}{|c|}{$\begin{array}{l}\text { Paternal } \\
\text { Support } \\
\text { Scale }\end{array}$} & \multicolumn{2}{|c|}{$\begin{array}{c}\text { Paternal } \\
\text { Independence } \\
\text { Scale }\end{array}$} & \multicolumn{2}{|c|}{$\begin{array}{c}\text { Paternal Relationship } \\
\text { Scales }\end{array}$} \\
\hline & & Mean & $p$ & Mean & $p$ & Mean & $p$ \\
\hline $\begin{array}{l}\text { Source of Financial } \\
\text { Support }\end{array}$ & $\begin{array}{l}\text { Parent } \\
\text { Self }\end{array}$ & & & $\begin{array}{l}55.07 \\
52.28\end{array}$ & 0.011 & $\begin{array}{l}104.17 \\
92.70\end{array}$ & 0.003 \\
\hline Parent's marital status & $\begin{array}{l}\text { Married } \\
\text { Not married }\end{array}$ & & & $\begin{array}{l}57.09 \\
51.44\end{array}$ & 0.010 & $\begin{array}{l}109.40 \\
89.72\end{array}$ & $<0.000$ \\
\hline
\end{tabular}

* For the categories that do not equal $100 \%$, the missing percentages represent the participants who did not provide a response for that question.

\section{Discussion}

Literature explicating risks for the development of eating disorders identify age, female gender, and Caucasian race as associated factors (Pratt \& Woolfenden, 2002). The current study did not find any significant difference in attachment related to age, and no difference in scores was demonstrated in relationship to race of the participant. However, this study was in a homogenous group ranging in age from 19 years of age to 25 years of age, and it is possible that the narrow age range as well as other similar sociodemographic characteristics may account for these finding. Other analyses included sorority membership and parent's marital status. In a previous study sorority membership was a contributing factor in unhealthy eating behaviors (Basow, et al., 2007); however the current study does not support the earlier finding. Insecure attachment may occur among youth of divorced parents (Crowell et al., 2009). The current study lends support to the conclusion that more secure parental attachment may exist when parents are married by demonstrating higher mean scores on both maternal and paternal scales, indicating more secure attachment.

Previous studies examining eating disorder variables have not reported clear differences in the attachment variables by parent (mother versus father) (May, et al., 2006; Tereno, et al., 2008). The current study demonstrated some clear differences. For example, healthy eating behaviors 
that produced significant findings on the maternal attachment scales were not replicated on paternal scales. The paternal scales significant findings were for demographic variables only, with neither eating behavior associated with a higher score of attachment. These findings suggest that late adolescent females have developed differences in attachment to the mother versus attachment to the father.

The current study findings suggests that secure maternal attachment was associated with reporting healthy eating habits such as at least three meals per day and no reported self induced vomiting. Although the study did not find significant differences in paternal attachment related to eating behaviors, the scores did demonstrate a greater level of attachment to the father when financial support was provided by parents. Existing studies exploring parental financial support and eating behaviors were not found, but previous studies did report that insecure attachment to the father may be a factor in the development of eating disorders (Gutzwiller, et al., 2003). It is possible that late adolescent females consider financial support as indicative of protection and attention by the father and perhaps this provides the secure base required for exploration of the environment.

\section{Limitations}

Several limitations should be noted. First, this study was completed in a non-clinical population and is not representative of females diagnosed with or who are being treated for eating disorders. Second, the primary investigator was an undergraduate research fellow who with the oversight of a faculty mentor devised a tool that assessed eating behaviors. Clearly the Eating Behavior Survey has not been used in prior research and lacks reliability and validity data, but content validity was established through expert opinion of practicing nurses. Third, this was a cross-sectional study and was not able to capture whether the reported behaviors were new, the same, or worse than before, nor can any causality be implied.

Of the 1668 emails sent, only 249 students participated in the complete survey, resulting in a lower than expected response rate. This low response rate may have affected the overall results. Additionally, the sample consisted of a fairly homogenous group of females from one geographic area of the United States, and therefore is not representative of the general population.

\section{Implications and Future Research Direction}

Clarification of variables affecting parental attachment should produce results to aid in the development of interventions to change eating behaviors in adolescents in general and in late adolescent females in particular. For example if mothers were provided with information about fostering independence in daughters this could enhance attachment levels on Maternal Independence Scales and may help to encourage females to make appropriate eating behavior choices, such as three or more meals daily.

The results of this study create some interesting ideas for future study. It was unexpected to find no significant differences in mean scores on paternal scales related to eating behaviors, because literature investigating female's attachment to their father in regards to eating disorders does suggest significant relationships (Gutzwiller, et al., 2003). Future research with a proven valid and reliable tool will help to clarify these findings. Additionally, ongoing research of eating behaviors should compare parental attachment in single-parent families with parental attachment in married parent families. The use of the PAQ in a clinical population could be beneficial in suggesting approaches to treatment of eating based on increasing secure parental attachment. 
In conclusion, this online survey of late adolescent female identified healthy eating behaviors related to higher levels of maternal attachment and identified sociodemographic variables associated with a greater level of paternal attachment. To our knowledge this is first the study of eating behaviors and sociodemographic variables that examine maternal and paternal attachment separately in this population. The findings indicate that relationships between maternal attachment and healthy eating behaviors exist; supporting previous studies that maternal attachment is significant in relation to eating behaviors. The study found no differences in paternal attachment scores in relation to eating behaviors, but did reveal sociodemographic variables related to paternal attachment. Parent's marital status was the only category that was significant for both the maternal and paternal scales, suggesting that there may be other undiscovered variables that affect both maternal and paternal attachment.

ACKNOWLEDGMENT: We wish to acknowledge that this undergraduate research project could not have been completed without the support and mentorship of the McNair Scholars Program, The University of Alabama.

\section{References}

Basow, S., Foran, K., \& Bookwala, J. (2007). Body objectification, social pressure, and disordered eating behavior in college women: The role of sorority membership. Psychology of Women Quarterly 31(4) 394-400.

Berry, T. \& Howe, B. (2000). Risk factors for disordered eating in female university athletes. Journal of Sport Behavior, 23(3), 207-218.

Cooley, E. \& Toray, T. (2001). Body image and personality predictors of eating disorder symptoms during the college years. International Journal of Eating Disorders, 30(1), 28-36.

Crowell, J., Treboux, D., \& Brockmeyer, S. (2009). Parental divorce and adult children's attachment representations and marital status. Attachment \& Human Development, 11(1), 87101.

Dallos, R. \& Denford, S. (2008). A qualitative exploration of relationship and attachment themes in families with an eating disorder. Clinical Child Psychology and Psychiatry, 13(2), 305-322.

Eggert, J., Levendosky, A., \& Klump, K. (2007). Relationships among attachment styles, personality characteristics, and disordered eating. International Journal of Eating Disorders. $40(2), 149-155$.

Ellison, C.G., Bradshaw, M., Rote, S., Storch, J., \& Trevino, M. (2008). Religion and alcohol use among college students: Exploring the role of domain-specific religious salience. Journal of Drug Issues, 8(3), 821-846.

Forrest, K.Y.Z. \& Forrest, A.G. (2008). Correlates of risky weight-control behaviors in adolescents. American Journal of Health Studies, 23(1), 1-8. 
Frey, L.L., Beesley, D., \& Miller, M.R. (2006). Relational health, attachment, and psychological distress in college women and men. Psychology of Women Quarterly, 3, 303-311. DOI: 10.1111/j.1471-6402.2006.00298.

Gutzwiller, J., Oliver, J., \& Katz, B. (2003). Eating dysfunction in college women: The role of depression and attachment to fathers. Journal of American College Health, 52(1), 27-32.

Holmbeck, G.N., \& Wandrei, M.L. (1993). Individual and relational predictors of adjustment in first-year college students. Journal of Counseling Psychology, 40, 73-78.

Hudson, J., Hiripi, E., Pope, H., \& Kessler, R. (2007). The Prevalence and Correlates of Eating Disorders in the National Comorbidity Survey Replication. Biological Psychiatry, 61(3), 348-358.

Kenny, M. (1994). Scoring instructions for the Parental Attachment Questionnaire. Retrieved from https://www2.bc.edu/ kennym/PAQScoring.html

Kenny, M.E. (1987). The extent and function of parental attachment among first-year college students. Journal of Youth and Adolescence, 16, 17-29.

Kenny, M.E., \& Donaldson, G.A. (1991). Contributions of parental attachment and family structure to the social and psychological functioning of first-year college students. Journal of Counseling Psychology, 38, 479-486.

Kenny, M., \& Hart, K. (1992). Relationship between parental attachment and eating disorders in an inpatient and a college sample. Journal of Counseling Psychology, 39(4), 521-526.

Kenny, M. \& Sirin, S.R. (2006). Parental attachment, self-worth, and depressive symptoms among emerging adults. Journal of Counseling \& Development, 84, 61-71.

May, A., Kim, J., McHale, S., \& Crouter, A. (2006). Parent-adolescent relationships and the development of weight concerns from early to late adolescence. International Journal of Eating Disorders, 39(8), 729-740.

Pealer, L.N., Weiler, R.M., Pigg, R.M., Miller, D., \& Dorman, S.M. (2001). The feasibility of a web-based surveillance system to collect health risk behavior data from college students. Health Education and Behavior, 28(5), 547-559.

Pratt, B.M. \& Woolfenden, S. (2002). Interventions for preventing eating disorders in children and adolescents. Cochrane Database of Systematic Reviews, 2. DOI:10.1002/14651858. CD002891.

Rafiroiu, A.C., Sargent, R.G., Parra-Medina, D., Valois, R., \& Drane, J.W. (2007). Trends and subgroup differences in overweight perception and weight-control behaviors among high school adolescents. American Journal of Health Studies, 22(4), 199-210.

Tereno, S., Soares, I., Martins, C., Celani, M., \& Sampaio, D. (2008). Attachment styles, memories of parental rearing and therapeutic bond: a study with eating disordered patients, their parents and therapists. European Eating Disorders Review, 16(1), 49-58. 
Vivona, J. (2000). Parental attachment styles of late adolescents: Qualities of attachment relationships and consequences for adjustment. Journal of Counseling Psychology, 473), 316329.

Zhao, Y. \& Encinosa, W. (2009). Hospitalizations for eating disorders from 1999 to 2006. HCUP statistical brief \#70. Agency for Healthcare Research and Quality, Rockville, MD. Retrieved from http://www.hcup-us.ahrq.gov/reports/statbriefs/sb70.jsp

(C) Copyright of Journal of Youth Development $~$ Bridging Research and Practice. Content may not be copied or emailed to multiple sites or posted to a listserv without copyright holder's express written permission. Contact Editor at: patricia.dawson@oregonstate.edu for details. However, users may print, download or email articles for individual use.

ISSN 2325-4009 (Print); ISSN 2325-4017 (Online) 